\title{
Govorne prvine pri osnovnošolskem pouku retorike
}

Nina Žavbi, Alida Bevk

\section{Uvod}

Govorno sporazumevanje od vseh v njem sodelujočih govorcev zahteva tako upoštevanje različnih okoliščin sporazumevanja (kraj, čas sporazumevanja, besedilo, družbene okoliščine itd.) kot tudi obvladovanje različnih elementov besednega in nebesednega sporazumevanja. Besednemu sporazumevanju tudi $\mathrm{v}$ procesu izobraževanja posvečamo veliko pozornosti, pri čemer je pomembna vsebina, pogosto pa se pozablja na nebesedni del, ki je za učinkovito komunikacijo ključen - tako njegova vidna (mimi$\mathrm{ka}$, geste, premikanje v prostoru) kot slušna (barva glasu, intonacija in register, glasnost in hitrost govora, premori, artikulacija ipd.) komponenta. Za vsako govorjenje, tudi za obvladovanje treme, ki je predvsem pri javnem sporazumevanju velik problem, je pomemben pravilni aktivni dih (ki je še danes pogosto pri poučevanju zanemarjen ali pa napačno razumljen). Neverbalna raven je v vsakodnevnem sporazumevanju prepletena $\mathrm{z}$ verbalno, pogosto pa se z njo podrobneje ne ukvarja in se jo jemlje kot samoumevno - v izobraževalnem procesu je niti učenci niti učitelji v resnici ne obvladujejo v zadostni meri.

Nezadostno ukvarjanje $\mathrm{z}$ neverbalnim se odraža tudi v glasovni (ne) kvaliteti in (nezadovoljivi) govorni zmožnosti študentov, ki se vpišejo na AGRFT. Z lastno refleksijo pedagoškega dela, ki izhaja iz dolgoletne prakse pedagogov, ki se primarno ukvarjamo $\mathrm{z}$ umetniškim govorom na Ka- 
tedri za govor (Bevk, 2019; Podbevšek, 2019; Žavbi, 2019 idr.), s pregledom raziskav javnega govora $\mathrm{z}$ različnih zornih kotov (tako umetniški kot neumetniški govor) in sodobnih teorij s področja didaktike (Cvetek, 2005; Marentič Požarnik, 2011) smo razvili skupine vaj, ki jih prenašamo iz visokošolskega poučevanja umetniških profilov, predvsem bodočih igralcev, in jih prilagajamo osnovnošolskim učencem. Pri njih poskušamo ozaveščati pomembnost diha in neverbalne komunikacije (njene vidne in slušne komponente) ter tako ne samo prispevati k izboljšanju komunikacijskih veščin in veščin javnega nastopanja, ampak tudi k razumevanju človekovega diha (ki izhaja iz telesa) ter prepletenosti giba oz. telesa in govora. Predlagane vaje temeljijo na metodah, osredinjenih na učence in njihovo aktivnost, na globinskem pristopu $\mathrm{k}$ učenju in spodbujanju kritičnega mišljenja. Razumevanje diha in njegove soodvisnosti pri govorni izvedbi je podprto s pristopom Fitzmaurice Voicework ter $\mathrm{z}$ razumevanjem fiziologije, anatomije dihalnih poti ter avtonomnega živčnega sistema. Aplikacija teh pristopov se na UL AGRFT kaže kot uspešna in je torej v pravi modifikaciji primerna tudi za poučevanje govora pri pouku retorike v šolskih učnih vsebinah.

\section{Govorno nastopanje v procesu šolanja in kasneje}

Javno nastopanje je dejavnost, s katero se v sodobnem svetu srečujejo skoraj vsi izobrazbeni in profesionalni profili, zato se zdi nujno, da se tekom šolanja $\mathrm{z}$ učenjem veščin javnega sporazumevanja učenci srečajo kar najpogosteje. Prav tako naj bi bil učitelj zgled dobrega javnega govorjenja, pa ne le učitelj slovenščine in retorike, temveč učitelji vseh predmetnih področij. Pomembno vlogo pri tem ima tako formalno kot neformalno izobraževanje učiteljev.

Učenci se že $\mathrm{v}$ prvem razredu osnovne šole srečajo $\mathrm{s} t$. i. govornim nastopom, »kot učna obveznost pa je predviden pri številnih učnih predmetih v celotni izobraževalni vertikali« (Žagar et al., 2018: 48). Učitelj naj bi ustvarjal situacije,

ki učence spodbujajo, da postopoma in razvojni stopnji primerno spoznavajo in preizkušajo zakonitosti javnega nastopanja, da ozavestijo, kaj se med nastopom z njimi dogaja tudi na neverbalni ravni, da znajo opazovati nastop nekoga drugega /.../, in da se lasten nastop tudi naučijo reflektirati. (Ibid.: 48-49.)

Zelo podobne usmeritve preberemo tudi v prenovljenem učnem načrtu retorike. 


\section{Govorne komponente $\mathrm{v}$ prenovljenem učnem načrtu} obveznega izbirnega predmeta retorika

Obvezni izbirni predmet retorika v osnovni šoli se izvaja za učence devetega razreda.

V prenovljenem učnem načrtu iz leta 2019 je zapisan namen poučevanja retorike, ki je seznanjenje

s pojmi prepričevanja in argumentiranja, /.../s tehnikami prepričevanja, elementi prepričevalnega postopka, dejavniki uspešnega prepričevanja, $\mathrm{z}$ oblikami prepričevanja, s strukturacijo (prepričevalnega) govora in $\mathrm{z}$ vsestranskim ( $\mathrm{tj}$. besednim in nebesednim) obvladovanjem govorne situacije, /.../ z razliko med prepričevanjem in argumentiranjem, razlikovanjem med dobrimi in slabimi argumenti, elementi dobre argumentacije in (če čas in zanimanje to dopuščata) $\mathrm{z}$ nepravilnimi oz. nedovoljenimi argumentativnimi postopki. (Žmavc et al., 2019: 4.)

Načrt torej predvideva, da je poleg tega, da je potrebno zelo dobro premisliti in vedeti, kaj govorimo, pomembno tudi, kako govorimo - poleg besednega tudi nebesedno sporazumevanje, tako njegova vidna kot slušna komponenta. To se nam zdi ključno, saj na tak način - sistematično in celovito - ta vsebina ni pokrita v nobenem učnem načrtu za osnovno šolo. Učni načrt predvideva, da učenci že imajo izkušnje z govornim nastopanjem, ki so jih pridobili v šolskem sistemu do devetega razreda, da pa potrebujejo sistematično in celovito ukvarjanje $\mathrm{z}$ vsemi elementi nastopa. Tako lahko učenci nadgradijo nekatere deloma že pridobljene kompetence in znanja. Poleg ustrezne priprave in izvedbe govornega nastopa učenci »razvijajo zmožnost ustreznega (samo)opazovanja in (samo)vrednotenja javnega govornega nastopa « (Žmavc et al., 2019: 5), kar je bilo v preteklosti pogosto (po besedah učiteljev in učencev) izpuščeno - brez ustreznega (samo)ovrednotenja izvedenega govora namreč ni napredka - s (samo)refleksijo učenci opazujejo nastope ostalih in sebe, se urijo v opazovanju in ubesedovanju videnega ter ugotavljajo, kaj je bilo izvedeno dobro in kje so možnosti za napredek. Hkrati soočajo različna mnenja. V svojih naslednjih nastopih se lahko poskušajo izboljšati in ugotavljajo učinke spremenjenih pristopov.

V operativnih ciljih prenovljenega učnega načrta so govorne vsebine eksplicitno in sistematično izpostavljene. Zapisano je, da učenci 
»spoznajo temeljne govorne slušne (razločnost, mašila, register, intonacija, ritem, hitrost in glasnost govora) in vidne (mimika, očesni stik, geste, obnašanje telesa, npr. postavitev/sedenje) prvine nastopa, dih in obvladovanje prostora ter njihov pomen za uspešno/neuspešno prepričevanje; pripravijo kratek govorni nastop in s (samo)opazovanjem ozavestijo prvine nastopa; opazujejo različne govorne nastope in razmišljajo o dejavnikih uspešnega/neuspešnega nastopa (trema, dobra/slaba predpriprava, nenačrtovane spremembe); razvijajo in krepijo spretnosti nastopanja (vaje za sproščanje, ogrevanje glasu in telesa; telo $\mathrm{v}$ začetnem govorniškem položaju; glasno branje; obvladovanje nepredvidenih zapletov med izvedbo). (Žmavc et al., 2019: 7.)

Do devetega razreda so učenci že veliko nastopali, pri različnih predmetih, predvsem pa pri pouku slovenščine (po celotni osnovnošolski vertikali, od prvega razreda naprej), saj razvijanje govornega nastopanja predstavlja enega od operativnih učnih ciljev, razvita zmožnost govornega nastopanja pa enega od standardov znanja (Žmavc, 2019: 80). Izhajajoč iz učnih načrtov pa umanjka sistematičnost in procesnost, postopnost - učenci tako ne nadgrajujejo svojega znanja, ampak nastop vedno obravnavajo kot celoto (Ibid.), o njem ne razmišljajo dovolj sistematično. Iz tega sledi, da so učenci o nastopu pred izvedbo težko poglobljeno razmišljali in ga na celosten način načrtovali - torej razumeli, da je vnaprej treba misliti izvedbo v luči nebesednih prvin in diha. Prav tako se $\mathrm{z}$ dihom in tremo niso soočali razumsko (saj ta dva segmenta $v$ učnih načrtih nista obravnavana kot učna vsebina), ampak so se $\mathrm{z}$ obema le borili in ju skrivali. Po nastopu po pričevanju študentov Akademije za gledališče, radio, film in televizije pogosto niso prejeli prave povratne informacije (čeprav učni načrti slovenščine omenjeno refleksijo predvidevajo), ki bi presegla analizo vsebine povedanega, zato v sami izvedbi niso mogli napredovati. Dejavnosti pred in po nastopu so torej pogosto umanjkale ali pa niso bile naslovljene $\mathrm{z}$ zadostno pozornostjo - menimo, da so to tiste dejavnosti, ki so $\mathrm{v}$ procesu učenja govornega nastopanja najpomembnejše, predvsem je pomembno ozaveščanje, da se je za govorjenje nujno pripravljati in da dober govorec postaneš šele $s$ trdim delom in $z$ učenjem iz lastnih napak. Učitelj retorike ima pomembno motivacijsko vlogo, predvsem pri vzpostavitvi varnega okolja, v katerem govorec z zaupanjem lahko sprejme dobronamerno konstruktivno kritiko, s pomočjo katere raste in se izboljšuje. Prenovljeni učni 
načrt predvideva tudi to, da se učenci naučijo na primeren način podati povratno informacijo, s pomočjo katere govorec lahko napreduje.

$\mathrm{V}$ prenovljenem učnem načrtu so opredeljene tudi z govorom povezane vsebine, in sicer »besedno in nebesedno sporazumevanje; izvedba govora; prvine izvedbe govora; osnove opazovanja govornega nastopanja « (Žmavc et al., 2019: 7). Učenci torej govorno nastopanje spoznajo tudi kot vsebino. Prvine neverbalnega sporazumevanja spoznajo sistematično in ugotavljajo, kako pomembne so pri nastopu. Te prvine nato preizkušajo pri izvedbi lastnega nastopa in jih opazujejo pri izvedbah sošolcev ter pri izvedbah nekaterih javnih govorov. V minimalnih standardih znanj je predvideno, da učenec

/p/ozna osnovne principe retorične tehnike in izkaže sposobnost njihove uporabe, tako, da pozna vseh pet temeljnih retoričnih postopkov za pripravo govora; si ogleda živ nastop ali posnetek primera govornega nastopa in s pomočjo osnovnih besednih in nebesednih kriterijev za vrednotenje nastopa usmerjeno opazuje izvedbo; razčleni posamezne besedne in nebesedne elemente

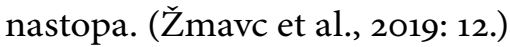

Učenec torej opazuje in vrednoti uporabo retorične tehnike $\mathrm{v}$ govoru drugih - analitična in vrednotenjska zmožnost, nato pa »samostojno oblikuje govor, v katerem uspešno prikaže uporabo temeljnih nebesednih prvin govornega nastopa« (Ibid.). Po lastni izvedbi jo poskuša samoovrednotiti.

$\mathrm{V}$ prenovljenem učnem načrtu retorike je predvideno, da učenec pridobi mnogo znanj in kompetenc, povezanih $\mathrm{z}$ nebesedno ravnjo sporazumevanja, popolnoma nova tema pa je aktivni dih ter obvladovanje in razumevanje treme $\mathrm{z}$ njegovo pomočjo.

\section{Glas in dih v povezavi s tremo pri pouku retorike}

Prenovljeni učni načrt retorike za osnovne šole predvideva nova poglavja na področju diha in njegove sorazmerne povezave s tremo in aktivnim govorom. Ta pridobljena znanja sodijo predvsem $\mathrm{k}$ pripravi ter izvedbi govornega nastopa.

Trema ${ }^{1}$ je eden izmed pojavov, ki večino človeške populacije prežema $\mathrm{s}$ strahom in s tem odbija posameznike od aktivne izkušnje $\mathrm{z}$ govornim

$\mathrm{V}$ obeh odstavkih, $\mathrm{v}$ katerih razlagamo naše razumevanje diha, telesa in treme ter soočanja s tremo se naslanjamo na Fitzmaurice Voicework, izhajajoč iz treh prispevkov (Cazden, 2017; Collwitz, 2016; Hague et al., 2016). 
nastopom. Velikokrat je že prvo soočanje $z$ govornim nastopom in izpostavljenostjo pred publiko tisto, ki zaznamuje posameznika morda za vse njegovo življenje, da se nastopanja boji ter se ga izogiba. Navadno se prva izkušnja zgodi ravno v osnovni šoli.

Trema je fiziološki pojav, ki je v svojem bistvu globoko vezana na dih oziroma na pomanjkanje diha. Gre za nezaveden odziv avtonomnega živčnega sistema, ki je odgovoren za uravnavanje osnovnih življenjskih funkcij (in s tem tudi diha) ter se odziva na prvotne, osnovne obrambne mehanizme, ki so v možganskem deblu - tako imenovani odziv beg/boj/zamrznitev (flight/fight/freeze response). Strah pred nastopom lahko v telo vstopa postopoma, ne da bi se posameznik tega zavedal, tako da košček za koščkom krči mišice okoli reber, trebuha, ramenskega obroča, saj je za strah značilna obramba, da se človek naredi čim manjšega, da bo neprijetno izkušnjo preživel tako, da ga čim manj prizadene. Tako postopoma prihaja do imobilizacije, ne da bi se posameznik tega zavedal. Težava je v tem, da so mišice okoli reber in trebuha, ki varujejo naše vitalne organe, ključne za dih in s tem posledično tudi za govor. $S$ tem, ko se krči naše telo, se krči tudi dihalna pot. Ko je dihalna pot popolnoma zožana in je posameznik tik pred nastopom, se v telesu sproži fiziološki proces, ki začne telo rahljati, osvobajati in odpirati, da omogoči prosto dihalno pot ter vrne življenje v od strahu zamrznjeno telo. Ti procesi so lahko vidni v tresenju posameznikovih okončin ali celotnega telesa, tresenju glasu, potenju, plitvem dihanju, pospešenem bitju srca, zardelosti ipd. Ta fiziološki odziv imenujemo trema in je v našem okolju stigmatiziran. Študenti nam povedo, da se napotki v šolah še vedno najpogosteje nanašajo na zakrivanje nelagodja pri nastopanju, npr. umiritev tresenja rok in telesa, pri čemer pa se zgodi ravno obratno, saj se nato tresejo še bolj, treme pa ne premagajo. Fiziološki odzivi so resda neprijetni, ker pogosto posameznika opominjajo na to, da izgublja nadzor nad situacijo in nad sabo, v resnici pa je trema proces, ki pomaga vzpostaviti ravnovesje preobremenjenega živčnega sistema ter pripraviti telo na nalogo, ki je pred njim.

$\mathrm{Na}$ tako predstavljen način postane učencem lažje razumljena, hitreje se lahko izognejo neprijetnim oznakam sramu in strahu ter jo lahko sprejmejo kot normalen biološki pojav.

Določene mišice, ki se ob strahu zakrčijo in ob tremi sprostijo, so ključne za vzpostavitev kvalitetnega aktivnega diha, ki ga potrebujemo pri govoru. Hkrati pa trema in njeni fiziološki procesi že učijo posameznike, da je organski dih neenakomeren, abrupten, ter da več zraka prihaja v telo 
skozi usta kot skozi nos. Tak dih je dih govora - aktiven, spontan, poln življenja in sposoben odzivanja na trenutni miselno-govorni proces.

V slovenskem prostoru v povezavi z govorom tudi strokovnjaki s področja govora največkrat omenjajo prepono, pogosto navodilo je: »dihaj s prepono, govori s prepono « (Bevk, 2019: 199), vendar pa njenega delovanja pogosto ne razumejo pravilno in ga ne znajo pravilno razložiti. S sledenjem napačnim navodilom

se lahko zgodi, da trebuh navzven in navznoter pomikamo le z mišicami, prepona pa pri tem dostikrat ostane bolj ali manj na istem mestu. Zato se je za premik trebuha vedno bolje osredotočiti na premik reber, saj si s tem lažje zagotovimo premik prepone. Ob naravnem, nestrukturiranem izdihu se trebuh enostavno in mehko pomakne navznoter $\mathrm{v}$ svojo prvotno obliko (Bevk, 2019: 202).

Prvi sklop mišic, ki aktivirajo dih, so medrebrne mišice, zelo kratke in pogosto popolnoma zanemarjene mišice, ki premikajo rebra pri vzdihu narazen in navzgor ter jih pri izdihu spuščajo proti medenici. Brez dviga reber se prepona ne more spustiti v trebušno votlino. Naslednji sklop mišic so posamezne plasti trebušnih mišic. Tiste, ki se prve skrčijo in delujejo kot zaščita pred nevarnostjo, so velika ravna trebušna mišica (rectus abdominis) in poševne trebušne mišice (obliquus abdominis). Te so vpete visoko na rebra in onemogočajo mehek in zdrav pritisk zraka na glasilke - zdrav govor. Edina mišica, ki pomaga pri zdravem tvorjenju glasu, je velika prečna trebušna mišica (transvesus amdominis). »Pomembna pa je, ker pri nezavednem, avtomatskem izdihu refleksno potisne trebušno vsebino nazaj v prvotno stanje in tako dvigne abdominalni tlak - s tem pa pomaga dvigniti, sprostiti tudi prepono. Prav to gibanje si želimo pri govoru ozavestiti, saj je osnova za zdrav, poln glas in govor.« (Bevk, 2019: 203) Razslojevanje mišic je $\mathrm{v}$ svojem pristopu poučevanja glasu izvrstno izdelala Catherine Fitzmaurice (1997, 2003), ki je tudi ena izmed redkih (če ne celo edina), ki je vpeljala $\mathrm{v}$ poučevanje govora in glasu pomembnost velike prečne trebušne mišice.

Dih in njegova fiziološka pot zaradi svoje izjemne pomembnosti pri govornem nastopanju v prenovljenem učnem načrtu retorike postaneta del priprave ter same izvedbe govora. 


\section{Kako pri retoriki poučevati govorne vsebine - didaktična priporočila}

$\mathrm{V}$ prispevku navedena znanja in kompetence uspešno poučujemo $\mathrm{z}$ učnimi metodami in oblikami, osredinjenimi na učenca. V sodobnih teorijah poučevanja in učenja je osredinjenost na učečega vse bolj izpostavljena Cvetek omenja pomembnost spremembe paradigme $\mathrm{v}$ »učenjsko« (Cvetek, 2005: 14), pri kateri je učenec in njegova dejavnost v ospredju. Podobno je značilno tudi za sodobni visokošolski študij, pri katerem se vse bolj poudarja nezadostnost zgolj podajanja znanja v obliki informacij pri t. i. tradicionalnih predavanjih, ampak nujnost kombiniranja teh $\mathrm{z}$ bolj interaktivno usmerjenimi oblikami in metodami. Visokošolski didaktiki zato priporočajo t. i. interaktivna predavanja (Marentič Požarnik in Lavrič, 2011: 18). Iz lastne več kot desetletne prakse s poučevanjem govora bodočih igralcev, iz študentskih anket in individualnih razgovorov s študenti lahko zaključimo, da je za kvaliteto študija izjemno pomembno, da so študenti pozitivno motivirani (tako zunanje kot notranje), da je pridobljeno znanje ozaveščeno (je učenje problemsko, $\mathrm{z}$ razumevanjem) ter da se $\mathrm{v}$ procesu učenja dobro počutijo (Žavbi, 2019: 186). V prenovljenem učnem načrtu retorike so te sodobne smernice upoštevane - predvideno je, da učenci pridobijo ustrezne kompetence, da je znanje ozaveščeno in (tudi) na višjih taksonomskih ravneh, učitelj pa $\mathrm{z}$ individualiziranim procesom, prilagojenim situaciji poskrbi za dobro in varno počutje v razredu (nujno pri učenju govornega nastopanja) in za pozitivno motivacijo - tudi s stalno povratno informacijo.

Tudi didaktična priporočila so pripravljena $\mathrm{v}$ tej smeri. Zato predlagamo nekaj skupin vaj, izhajajočih iz poučevanja govornega nastopanja študentov Dramske igre, prilagojenih osnovnošolskim učencem. Vaje so koncipirane tako, da izhajajo iz besedila prenovljenega učnega načrta ter iz sodobnih didaktičnih pristopov. ${ }^{2}$ Učitelj pa je v svoji profesionalni avtonomnosti toliko fleksibilen, da jih prilagaja in modificira, lahko pa so mu le izhodišče za razmišljanje, kako samostojno koncipirati pouk, da poma-

2 Sodobna didaktična priporočila, ki jih poskušamo upoštevati v visokošolskem izobraževanju, prav tako pa se jih da aplicirati tudi na osnovnošolski pouk retorike, zajemajo metode in oblike, osredinjene na učečega, npr. skupinske razprave, sodelovalno učenje itd., uporabo različnih didaktičnih sredstev, npr. avditivnih in avdiovizualnih, tudi uporabo e-virov, spodbujanje $\mathrm{h}$ globinskemu pristopu $\mathrm{k}$ učenju in doseganju višjih taksonomskih ravni spoznavnih ciljev, poleg zaključnega tudi diagnostično (začetno) ter formativno (sprotno) preverjanje znanja, ki omogoča stalno povratno informacijo in napredek. 
ga učencem pri čimbolj samostojnem razvijanju različnih govornih spretnosti.

\section{1. skupina vaj - poslušanje drugega in sebe}

Da lahko dobro govorimo, moramo najprej dobro usmerjeno poslušati. Aktivnost poslušanja ni tako lahka, kot se zdi na prvi pogled, saj pogosto poslušamo zelo površinsko in selektivno. Ta vaja učence navaja na skoncentrirano poslušanje ter na analizo in vrednotenje tega, kar smo slišali. Naloga je sestavljena iz treh dejavnosti - poslušanja, razmišljanja o slišanem in ubeseditve teh spoznanj.

Vedno začnemo s poslušanjem drugega - lahko je to sošolec, lahko je tudi javni govorec. Po usmerjenem poslušanju si učenci zapišejo svoja opažanja ob slišanem, nato sledi ubeseditev opažanj in soočenje različnih stališč učencev. Učenci opazujejo tako slušne prvine, npr. kakšen je glas, ali je prijeten/neprijeten, kakšna je barva glasu, hitrost govora, ritem, razumljivost izgovora itd., kot tudi vidne prvine govora, npr. kakšna je govorčeva mimika, kakšne so geste in obvladovanje prostora, kaj se dogaja z očesnim stikom ipd. Glede na to učenci na koncu vrednotijo, ali je način govornega nastopanja učinkovit in svojo odločitev utemeljujejo. Pri tem je pomembno, da ne izhajajo iz osebnega mnenja, ampak svoje komentarje utemeljijo $s$ koncepti/pojmi o slušnih in vidnih prvinah govora. Zato je smiselno, da se vaja izvaja po tem, ko so pri pouku retorike že vsebinsko podrobneje obravnavali neverbalne spremljevalce govora. Vaja je lahko tudi uvod v vsebino (tako ima bolj motivacijsko vlogo), kasneje pa se jo lahko izvaja pri analizi in povratni informaciji ob izvedbah govornih nastopov.

Iz te izhajajoča druga vaja je poslušanje sebe. Izvede se jo podobno kot prvo različico, le da posameznik posluša svoj govor in ga analizira - poskuša opisati svoj lastni govor in ga ovrednotiti. Vaja je namenjena ozaveščanju prvin lastnega govora, ki po več izvedbah omogoča tudi samoizboljšave.

Zanimiva za glasovno kreativnost je vaja t. i. zvočnega zrcala (Podbevšek, 2019: 195). Pri tej nalogi učenec izreče en stavek, drugi pa ga čimbolj v popolnosti ponovi (tako po slušni kot vidni komponenti). Gre za urjenje $\mathrm{v}$ poslušanju in ustvarjalnem govorjenju - imitiranju.

Prva skupina vaj je ogrevalna v smislu zavedanja lastnega glasu in njegove sporočilnosti in izrazne moči. Hkrati pa učence uri v eni od sporazumevalnih spretnosti, poslušanju. 


\section{2. skupina vaj-govorjenje različnih besedil (nepovezanost glasu in vsebine besedila)}

Druga skupina vaj je namenjena ozaveščanju sporočilnosti našega glasu (slušna komponenta) in telesa (vidna komponenta). Vsebina besedila in neverbalna sredstva govora so navadno povezana - če npr. beremo osmrtnico, glas in telo podčrtujeta vsebino, ki jo osmrtnica izraža. Zaradi prepleta teh sredstev se pomembnosti neverbalnega v vsakodnevni rabi ne zavedamo.

Vaje predvidevajo izbor besedilne predloge, ki jo bo govorec govoril $\mathrm{z}$ nasprotujočo intenco tisti, ki je razvidna iz besedila. Primer je branje recepta, npr. recepta za palačinke. Učenci recept berejo kot npr. ljubezensko pismo, prepir s starši ipd. Ostali učenci na koncu govorne izvedbe ugibajo, kaj je govorec poskušal izvesti. Vaja spodbuja glasovno ustvarjalnost in odpira pot ustvarjalni rabi glasu v govornem nastopanju. Lahko se jo uporablja pri poučevanju vsebine, lahko pa kot motivacijo in ogrevanje pri raznih drugih učnih urah. Na koncu je smiselna poglobljena analiza neverbalnih govornih sredstev, ki so bila uporabljena pri izvedbi - učenci se tako zavedo, da sama raba sredstev signalizira vsebino, ki jo sporoča.

\section{3. skupina vaj - vaje pri izvajanju govornega nastopa}

Tretja skupina vaj je povezana s poučevanjem retorične tehnike in z izvedbo govornega nastopa. Pri tem lahko kombiniramo različne vaje, odvisno od skupine učencev. Če so učenci nastopanja že precej vešči in se v skupini počutijo dobro in varno, lahko naredimo zabavno vajo, ki učence poskuša pripraviti na nepredvidljivost javnega nastopa. Nepredvidljivost različnih dejavnikov je namreč stalnica vseh javnih govornih nastopov.

$V$ razredu izberemo govorca in skupino poslušalcev ter skupino opazovalcev celotnega procesa. Dva poslušalca dobita dodatni nalogi motilcev govora - npr. eden ves čas klepeta, eden ves čas sprašuje. Med govorom nato opazujemo, kako se govorec znajde $v$ tej situaciji, kako reagirajo ostali poslušalci ipd. Na koncu vaje naredimo evalvacijo situacije $-\mathrm{s}$ pomočjo govorca, poslušalcev in opazovalcev. Učenci poskušajo analizirati svoja občutenja in odzivanje na situacijo ter analizirajo, kako bi se lahko odzvali bolje.

\section{4. skupina vaj-čutenje gibanja telesa preko zaznave diha}

Prva vaja je namenjena ugotavljanju, kako se dih obnaša v govorni situaciji in kaj sploh pomeni aktivni dih. Navadno učenci globok in kvaliteten dih povezujejo s pretiranim vlečenjem diha skozi nos in dvigovanjem ramen. 
Ob tem jim ponudimo dve možnosti: da govorijo, ne da bi mislili na dih, in da vdihnejo skozi nos, govorijo in, ko jim zmanjka zraka, zopet vdihnejo skozi nos. Nato primerjajo in ugotavljajo, pri katerem načinu se bolje počutijo in kaj se jim zdi bolj naravno.

Naslednje vaje so namenjene občutenju premika reber ter diferenciaciji trebušnih mišic. Da bi najbolje sprostili rebra in pridobili elastičnost medrebrnih mišic, prosimo učence, da za začetek $\mathrm{v}$ domačem okolju poiščejo površine, kjer se lahko zleknejo po površini tako, da glava prosto visi, trup pa je upognjen, npr. čez kavč, čez blazine, velike žoge ipd., v šoli pa morda čez primerne stole, tudi žoge, če so na voljo. Najboljši pripomoček je zafu, meditacijska blazina. Tak razteg omogoča, da se čeljust razpre, da opazujemo pretok zraka tudi skozi usta, če pa se osredotočimo na trebušno votlino, ob izdihu lahko zaznamo mehko spuščanje trebuha in to je velika prečna trebušna mišica. Po takem raztegu učence prosimo, da roke namestijo na rebra in opazujejo dvig in spust rebrnega obroča. Roke premaknejo pod pazduho ter kasneje na ključnico ter primerjajo in opazujejo premik.

Za diferenciacijo trebušnih mišic jim lahko damo tri naloge. Prva je, da izvajajo klasične trebušnjake in hkrati govorijo, pri čemer se občuti predvsem delo velike ravne trebušne mišice (rectus abdominis), druga je izvajanje trebušnih navzkriž (nasprotni komolec $\mathrm{k}$ nasprotnemu kolenu), kjer se povežejo s poševnimi trebušnimi mišicami (obliquus abdominis), ter ležanje na tleh $\mathrm{z}$ mislijo, da si poskušajo zapeti pretesne hlače - to dejanje jih poveže $\mathrm{z}$ veliko prečno trebušno mišico (transversus abdominus). Namen te vaje je ugotavljanje, kdaj je govor najbolj enostaven, kdaj je najtežji ter kako in kje čutimo posamezne mišice. K tej analizi in občutenju se lahko vračamo vselej, ko začutimo, da nas boli grlo, da stiskamo, ter nam pomaga, da se lahko ponovno povežemo $\mathrm{z}$ naravnim dihom in veliko prečno trebušno mišico.

Predstavljene štiri skupine vaj za dih, glasovno izraznost in javno govorno sporočanje so le vzorec nekaterih možnosti. Pomembna je predvsem njihova ustvarjalna raba ter njihovo ovrednotenje na koncu. Brez zadnjega koraka - (samo)analize in (samo)ovrednotenja namreč tako vaje kot celotni proces učenja govornega nastopanja ne more biti uspešen, sploh pa ne ves čas napredujoč.

\section{Zaključek}

Prispevek je poskušal pregledno prikazati, kako se govorne komponente vključujejo v prenovljeni učni načrt obveznega izbirnega predmeta retori- 
ka in utemeljiti razloge za implementacijo teh vsebin v učni načrt. Poleg teoretične umeščenosti učnih vsebin smo želeli ponuditi konkretne primere vaj, ki izhajajo iz vaj za študij Dramske igre, prilagojenih razvojni stopnji in predznanju osnovnošolskih učencev $z$ upoštevanjem sodobnih didaktičnih usmeritev. Učitelji jih lahko uporabijo pri poučevanju govornih tem pri pouku retorike, pa če gre za učne vsebine ali le prvine, ki jih moramo obvladovati pri pripravi govornega nastopa. Vaje pripomorejo k razvoju govorne domišljije, k pridobivanju govorne samozavesti, ki jo učenci nujno potrebujejo, ter k premagovanju treme. Poskušali smo tudi prikazati pomembnost ozaveščanja lastnega diha, kar pripomore ne samo k izboljšanju govora, ampak tudi k premagovanju stresa in treme, kar je za sodobnega posameznika (tudi izven meja javnega nastopanja) izjemno pomembno.

\section{Literatura}

Bevk, Alida. »Vloga anatomije in fiziologije pri poučevanju govora.«V Govor v pedagoški praksi, ur. Katarina Podbevšek in Nina Žavbi, 199-205. Ljubljana: Znanstvena založba Filozofske fakultete in UL AGRFT, 2019.

Cazden, Joanna. »Stalking the calm buzz: how the polyvagal theory links stage presence, mammal evolution, and the root of the vocal nerve."Voice and Speech Review, 11, 2 (2017): 132-153.

Cvetek, Slavko. Poučevanje kot profesija, učitelj kot profesionalec. Radovljica: Didakta, 2005.

Fitzmaurice, Catherine. »Breathing is Meaning."V The Vocal Vision, ur. Marian Hampton, 247-252. New York: Applause books, 1997.

Fitzmaurice, Catherine. »Structured Breathing.« Vasta Newsletter 17, 1 (2003). https://static1.squarespace.com/static/5569e19fe 4 b o $2 \mathrm{fd} 687 \mathrm{f} 77 \mathrm{~b}$ of/t/5a754892c830259c5383c803/1517635731086/Structured+Breathing+2018. pdf (Dostop: 6. 6. 2019).

Hague, Daydrie, in Sandege, Mary J. »Evaluating the effects of stress reduction tehniques and Fitzmaurice Voicework ${ }^{\circledast}$ on physiologic markers and mental stages related to performance anxiety in student actors."Voice and Speech Review 10, 2-3 (2016): 121-130.

Kollwitz, Melissa. »Breath, tremoring, and performance anxiety: How can Fitzmaurice Voicework's Destructuring address performance anxiety in undergraduate acting training." Voice and Speech Review 10, 2-3 (2016): 100-120. 
Marentič Požarnik, Barica, in Lavrič, Andreja. Predavanja kot komunikacija: kako motivirati in aktivirati študente. Ljubljana: Znanstvena založba Filozofske fakultete, 2011.

Podbevšek, Katarina. Govornost literarnih besedil. Maribor: Aristej, 2017.

Podbevšek, Katarina. »Razvijanje izraznosti glasu pri študentih Dramske igre.« V Govor v pedagoški praksi, ur. Katarina Podbevšek in Nina Žavbi, 189-197. Ljubljana: Znanstvena založba Filozofske fakultete in UL AGRFT, 2019.

Tivadar, Hotimir. »Položaj slovenskega govora skozi prizmo stavčne fonetike - aktualizacija opisa osnovnih besedilnofonetičnih parametrov.«Jezik in govor 63, 2-3 (2018): 7-25.

Žagar Ž., Igor, Žmavc, Janja, in Domajnko, Barbara. Učitelj kot retorik: Retorično-argumentativni vidiki pedagoškega diskurza. Ljubljana: Pedagoški inštitut, 2018.

Žavbi, Nina. »Kako poučevati govor (izzivi sodobnega odrskega govora z vidika pravorečne norme).« V Govor v pedagoški praksi, ur. Katarina Podbevšek in Nina Žavbi, 181-188. Ljubljana: Znanstvena založba Filozofske fakultete in UL AGRFT, 2019.

Žmavc, Janja, Cestnik, Mojca, Žagar Ž., Igor. Učni načrt. Program osnovna šola. Retorika [Elektronski vir]: izbirni predmet. Ljubljana: Ministrstvo za izobraževanje, znanost in šport, Zavod RS za šolstvo, 2019.

Žmavc, Janja. Nekoč k retorju in gledališkemu igralcu - kam pa danes? (Poskus kritičnega pogleda na kurikularne umestitve govornega nastopa $\mathrm{v}$ okviru osnovnošolskega izobraževanja). V Govor v pedagoški praksi, ur. Katarina Podbevšek in Nina Žavbi, 75-83. Ljubljana: Znanstvena založba Filozofske fakultete in UL AGRFT, 2019. 